\title{
Consumer preference, antibacterial activity and genetic diversity of ginger (Zingiber officinale Roscoe) cultivars grown in Sri Lanka
}

\author{
L.R. Sendanayake', T.P. Sylvester ${ }^{2}$, U.H.A.J. De Silva², D.R.R.P. Dissanayake ${ }^{2}$, \\ D.M.K.C. Daundasekera ${ }^{2}$ and S.D.S.S. Sooriyapathirana ${ }^{2^{*}}$
}

Received: 11 th August 2016 / Accepted: $3^{\text {rd }}$ February 2017

\begin{abstract}
Ginger is a medicinal plant and a valuable spice. The present study was conducted to assess the consumer preference, antibacterial activity and genetic diversity of local ginger in comparison to the Chinese and Rangoon ginger cultivars grown in Sri Lanka. The ginger samples were collected from five districts. The preferred colour, aroma and degree of pungency of rhizomes were recorded by employing a taste panel and the data were subjected to association analysis. The antibacterial activity of the ginger samples were tested against two model pathogens Escherichia coli (JM 109) and Staphylococcus aureus (NCTC 4838) using methanol extract of rhizomes using the paper disc method and measured as diameter of zone of inhibition (DZBI). The DNA extracts of the three cultivars were subjected to PCR, using DNA barcoding primers trnH-psbA, followed by DNA sequencing, alignment and cluster analyses. Two trnH-psbA sequences of Zingiber officinale and Curcuma longa (as out-group) available in GenBank were used for comparison. There were significant associations among ginger cultivars in colour, pungency and aroma. The highest preferred colour was observed in Chinese ginger and the highest degree of pungency and highest preferred aroma were observed in Local and Rangoon gingers. All ginger samples collected exhibited at least $6 \mathrm{~mm}$ of DZBI. E. coli was less affected by methanol extract compared to $S$. aureus. A clear PCR amplicon was obtained for all three gingers. Another second amplicon of lesser intensity was also observed for Chinese and Rangoon gingers. DNA sequencing helped to generate a clear sequence for local ginger but no sequences were obtained for Chinese and Rangoon gingers. This could be due to the presence of second amplicon that would have inhibited DNA sequencing. The DNA sequence based clustering revealed that local ginger is $0.8 \%$ different from the two Z. officinale sequences available in GenBank implying that local ginger in Sri Lanka is genetically different.
\end{abstract}

Keywords: Zingiber officinale, ginger cultivars, antibacterial activity, DNA barcoding, trnH-psbA

\section{INTRODUCTION}

Ginger, Zingiber officinale Roscoe, belongs to family Zingiberacae. Ginger is an aromatic herb renowned worldwide as a spice and a medicinal plant (Auta et al., 2011). It is a Polynesian perennial herbal plant in tropical Asia (Kambaska and Santilata, 2009) and the origin is believed to be South East Asia (Ravindran and Babu, 2005; Nmadu and Marcus, 2013). Ginger is well adapted to tropical and sub-tropical areas and predominantly grown in China, India and other South Asian countries, Africa, United States, Mexico and West Indies (Hasan et al., 2012; Ajav and Ogunlade, 2014). Ginger grows well in warm and humid climates (Yadav et al., 2004; Ravindran and Babu, 2005) having mean annual rainfall above $2000 \mathrm{~mm}$, optimum altitude within the range of 300 to $900 \mathrm{~m}$ above mean sea level (Pruthy, 1993; Ravindran and 
Babu, 2005). The economically important part of ginger is underground rhizome which is aromatic, fleshy and bares ring like scars.

Ginger is one of the mostly used traditional herbal medicinal plants having many reported ethno-medicinal and nutritional values making it an ideal candidate for drug discovery (Riaz et al., 2015). It has been used by human beings since prehistoric times (Sasidharan and Menon, 2010). Ginger is used in Ayurveda, Siddha, Chinese, Arabian, African and Caribbean traditional medicinal systems (Prasad and Tyagi, 2015; Shamsi et al., 2010; Ghasemzadeh et al., 2010; Banerjee et al., 2011). Ginger is also a significant component in tibbe-unani, allopathic, aromapathic and household medicines. It is a frequently used component in herbal medicinal preparations against asthma, cough (Banerjee et al., 2011), nausea (Prasad and Tyagi, 2015) digestive disorders (Micklefield et al., 1999) rheumatism, gingivitis (Ali et al., 2008) and diarrhea (Ravindran and Babu, 2005). Ginger has antimicrobial activities reported against many pathogenic species such as Escherichia coli, Pseudomonas aeruginosa, Staphylococcus aureus, Klebsiella spp., Salmonella spp. and Proteus spp. (Akintobi et al., 2013; Hasan et al., 2012; Nikolic et al., 2014; Bhargava et al., 2012). Therefore, ginger is an essential component in treatments for many infectious diseases such as diarrhea and skin infection. Ginger is also found to be suppressing cancers in skin, gastro-intestinal tract, breast, cervix and brain (Dorai and Aggarwal, 2004). The nutritional composition and flavours of ginger are very important in medical and culinary preparations. Fresh ginger contains proteins, fat, carbohydrates, lipids, minerals, fiber, sodium, calcium, vitamins (Kumar et al., 2011) alkaloids, saponins, glycosides, volatile oils, shogaol, diarylheptanoids, gingerols, flavonoids and (Bhargava et al., 2012; Hasan et al., 2012). The characteristic pleasing pungency in ginger is due to the presence of phytochemicals, shogaol and gingerols (Jiang et al., 2005).
The DNA barcoding of plants, sequencing of the specific loci in plastid and nuclear genomes, is essential to identify the species accurately (Chase et al., 2005). The plant DNA barcoding can be done with numerous loci such as matK, $r b c L$ and trnH-psbA (Hollingsworth et al., 2009). The particular choice out of these loci is depending on the easiness of PCR amplification and the degree of divergence within the given taxa. The DNA barcoding has been efficiently employed to accurately identify the medicinal species such as Uncaria spp. (Zhang et al., 2015), Centella asiatica and Piper betle (Aziz et al., 2015). The GenBank (Benson et al., 2015, www.ncbi.nlm.nih.gov/genbank/), the universal database for DNA and protein sequences, contains many DNA barcodes (i.e. sequences) generated for numerous species in the family Zingeberaceae that have been employed to identify the species accurately. Although, two Z. officinale barcodes have been published in GenBank (GQ435045.1 and GQ435044.1 in Chen et al., 2010), the local ginger in Sri Lanka has not been subjected to DNA barcoding.

In Sri Lanka ginger is grown mainly in wet and intermediate zones (Department of Export Agriculture, Sri Lanka, 2012) and considered as a valuable cash crop. The major ginger cultivars grown in Sri Lanka are local ginger (LG) (Beheth Inguru or Siddha Ginger), Chinese ginger (CG) and Rangoon ginger (RG) (Department of Export Agriculture, Sri Lanka, 2012). Three ginger cultivars mentioned are morphologically very similar and only some differences can be seen regarding the size of the rhizomes. These morphological differences are always variable according to the environmental conditions that they grow. Limited studies have been reported on the quality parameters, antibacterial activity and genetics of ginger cultivars grown in Sri Lanka. The present study was conducted to assess the consumer preference, antibacterial activity with respect to the different districts that ginger is grown and DNA diversity of the ginger cultivars grown in Sri Lanka. 


\section{MATERIALS AND METHODS}

\section{Plant material}

Three major ginger cultivars grown in Sri Lanka namely, local ginger (LG), Chinese ginger (CG) and Rangoon ginger (RG) were used in the present study. The rhizome samples at harvesting stage were collected from five major ginger growing Districts, Gampaha, Kalutara, Kandy, Kurunagala and Matale, Sri Lanka. About $150 \mathrm{~g}$ of rhizome samples were collected from at least 15 plants in each District and stored in covered dried-sand until processing for methanol extraction. The immature leaf samples were also collected from the three ginger cultivars and stored at $-80{ }^{\circ} \mathrm{C}$ until DNA extraction.

\section{Assessment of consumer preference}

Dried rhizome samples were provided to a 25 panelists to rank them for the degree of pungency, preferred level of aroma and preferred level of colour. For each of these parameters, a threetier scoring system was employed and panelists were requested to assign 3 for the highest, 2 for the medium and 1 for the least in each parameter.

\section{Assessment of the antibacterial activity}

The fresh ginger rhizome samples were cleaned and cut into small pieces and air-dried until a constant weight was obtained. The dried rhizome pieces were ground using a sterilized food grade grinder. The methanol extraction of ground samples was performed using an ultrasonic bath (Branson ${ }^{\circledR}$ Ultrasonic Bath, $230 \mathrm{Vac}, 50 \mathrm{~Hz}, \mathrm{Z} 245100$ ). A total of $30 \mathrm{~g}$ each of powdered rhizome were dissolved in 60 $\mathrm{ml}$ of methanol and extract were obtained by filtering through Whatman filter paper no.2 (WHA1002125). Methanol in the filtrates was evaporated completely using a rotary evaporator to obtain a dried ginger extract. A total of 40 $\mathrm{mg}$ of extracted sample was dissolved in 10 $\%$ dimethyl sulfoxide (DMSO) to assess the antibacterial activity.
The microbial inocula were prepared for model pathogens Staphylococcus aureus (NCTC 4838) and Escherichia coli (JM 109) by culturing in Luria-Bertani (LB) broth overnight in a rotary shaker at $37{ }^{\circ} \mathrm{C}$. Each culture was compared with 0.5 McFarland solution to obtain the standard cell density. Antibacterial activity of ginger extracts were tested by Kirby-Bauer disc diffusion method (Bauer et al., 1966). A total volume of $20 \mathrm{ml}$ autoclaved MuellerHinton Agar (MHA) medium was poured into each sterile petri dish and allowed to solidify. Then $200 \mu \mathrm{l}$ of each bacterial cell culture was inoculated and spread on the MHA medium using a sterilized glass spreader. Sterilized paper discs (6 $\mathrm{mm}$ in diameter) were placed on the agar plate. A volume of $10 \mu \mathrm{l}$ of each extract was added to the paper discs separately. Negative and positive controls were also used with $10 \mu \mathrm{l}$ of DMSO and $10 \mu \mathrm{l}$ of Gentamicin, respectively. The inoculated plates were incubated at $37^{\circ} \mathrm{C}$ for 12 hours. The diameter of the zone of inhibition (DZBI) around each paper disc was measured and each experiment was performed in triplicate.

\section{DNA barcoding}

Genomic DNA from leaf samples were purified using cetyltrimethyl ammonium bromide (CTAB) method (Doyle and Doyle, 1987) and quantified using spectrophotometry and agarose gel electrophoresis. The polymerase chain reaction (PCR) was performed using standard universal plant DNA barcoding primer pair trnH-psbA (forward primer 5'GTT ATG CAT GAA CGT AAT GCTC3' and reverse primer 5'CGC GCA TGG TGG ATT CAC AAT CC $3^{\prime}$ ) (Sang et al., 1997). The PCR was performed in a thermal cycler (TAKARA, Japan, TP600) using 5 mins initial denaturation at $94{ }^{\circ} \mathrm{C}$, followed by 35 cycles of $30 \mathrm{sec}$ at $94^{\circ} \mathrm{C}, 90 \mathrm{sec}$ at $54{ }^{\circ} \mathrm{C}, 2$ mins and $30 \mathrm{sec}$ at $72{ }^{\circ} \mathrm{C}$ and final extension step at $72{ }^{\circ} \mathrm{C}$ for 10 mins. The PCR products were size separated using $1 \%$ agarose gel electrophoresis and subjected to Dideoxy DNA Sequencing (ABI 3500 Genetic Analyzer, 4405186). 


\section{Data analysis}

The external and internal appearance of the ginger rhizomes were observed and photographed. These preference parameters were subjected to association analysis using chi squared $\left(\chi^{2}\right)$ test and Cramer's V coefficient (CVC) available in the FREQ Procedure of the Statistical Package, SAS 9.1 (SAS Institute, Cary, NC, USA). The DZBI data was subjected to GLM Procedure in SAS considering the ginger cultivars and district as the independent variables. The trnH-pbsA sequences were subjected to multiple sequence alignment analysis with reference to published related DNA sequences of Curcuma longa (KC441355.1), Z. officinale (GQ435045.1 and GQ435044.1) available in GenBank. The Single Nucleotide Polymorphism (SNP) and insertion/ deletion (INDEL) differences in the sequence alignment were used to calculate the pair-wise Simple Matching Coefficients (SMC) (Dunn and Everitt, 1982) as given below.

$$
\mathrm{SMC}=([(\mathrm{a}+\mathrm{d})) /((\mathrm{a}+\mathrm{b}+\mathrm{c}+\mathrm{d})] \times 100)
$$

For a given sequence-pair of comparison,

$\mathrm{a}=\quad$ total number of times SNPs or INDELs present $(1,1)$

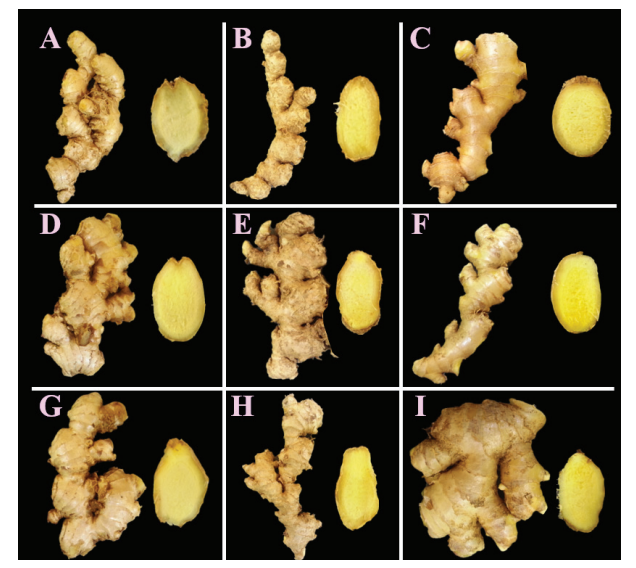

$\mathrm{b}=\quad$ total number of times SNPs or INDELs present in first sequence and absent in second sequence $(1,0)$

$\mathrm{c}=\quad$ total number of times SNPs or INDELs absent in first sequence and present in second sequence $(0,1)$

$\mathrm{d}=\quad$ total number of times SNPs or INDELs absent $(0,0)$

The SMC values generated for each pair of DNA sequences were used to construct the dendrogram using Unweighted Pair-wise Group Method (UPGM) using Single Linkage Method (Saitou and Nei, 1987).

\section{RESULTS}

\section{The morphology of the rhizomes}

The external appearance and cross sectional views of the mature ginger rhizomes of $\mathrm{CG}$, LG and RG were observed as in Figure 01 . There were no marked differences among the rhizomes of three ginger cultivars from the five Districts.

Figure 01: The external appearance and cross sectional views of mature ginger rhizomes. Scale bar represents $1 \mathrm{~cm}$. A, D, G, J, and M: Chinese ginger (CG), B, E, H, K and N: Local ginger (LG), C, F, I, L and O: Rangoon ginger (RG). A, B and C: Gampaha District; D, E and F: Kalutara District; G, H and I: Kandy District; J, K and L: Kurunegala District, M, N and O: Matale District.

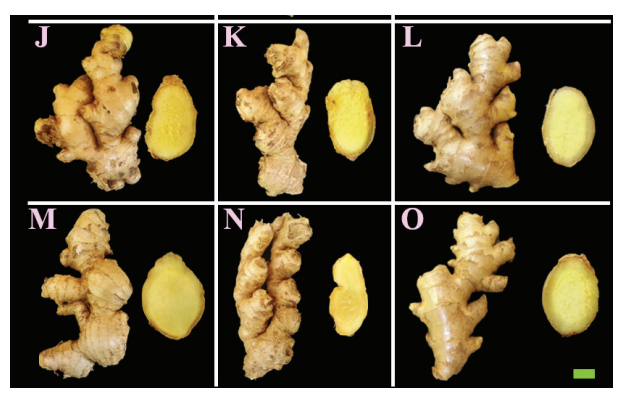


Association analysis of taste parameters among ginger cultivars

The association analysis of the tested parameters; degree of pungency, preferred level of aroma and preferred level of colour, revealed that there were significant associations between the ginger cultivar and colour $\left(\chi^{2}=50.00 ; \mathrm{CVC}=1.00\right)$ ginger cultivar and pungency $\left(\chi^{2}=19.84\right.$; CVC $=0.36)$ ginger cultivar and aroma $\left(\chi^{2}=13.00\right.$; $\mathrm{CVC}=0.50)$ and aroma and pungency $\left(\chi^{2}=\right.$ 17.44; $\mathrm{CVC}=0.34)$. The association between colour and pungency and colour and aroma were not significant at $P<0.05$ (Table 01).

Table 01: Association analysis of the taste parameters and ginger cultivars

\begin{tabular}{|c|c|c|c|c|}
\hline \multicolumn{5}{|c|}{ Ginger Cultivar vs. Preferred Level of Colour } \\
\hline \multirow{2}{*}{ Ginger Cultivar } & \multicolumn{3}{|c|}{ Preferred Level of Colour } & \multirow{2}{*}{ Test Statistics } \\
\hline & Low (1) & Medium (2) & High (3) & \\
\hline Chinese Ginger & $0 \%{ }^{\#}$ & $0 \%$ & $100 \%$ & $\chi^{2}$ value: 50.00 \\
\hline Local Ginger & $100 \%$ & $0 \%$ & $0 \%$ & Cramer's V Coefficient: 1.00 \\
\hline Rangoon Ginger & $0 \%$ & $100 \%$ & $0 \%$ & P value: $<0.0001$ \\
\hline \multicolumn{5}{|c|}{ Ginger Cultivar vs. Degree of Pungency } \\
\hline \multirow{2}{*}{ Ginger Cultivar } & \multicolumn{3}{|c|}{ Degree of Pungency } & \multirow{2}{*}{ Test Statistics } \\
\hline & Low (1) & Medium (2) & High (3) & \\
\hline Chinese Ginger & $72 \%$ & $16 \%$ & $12 \%$ & $\chi^{2}$ value: 19.84 \\
\hline Local Ginger & $20 \%$ & $36 \%$ & $44 \%$ & Cramer's V Coefficient: 0.36 \\
\hline Rangoon Ginger & $20 \%$ & $44 \%$ & $36 \%$ & P value: 0.001 \\
\hline \multicolumn{5}{|c|}{ Ginger Cultivar vs. Preferred Level of Aroma } \\
\hline \multirow{2}{*}{ Ginger Cultivar } & \multicolumn{3}{|c|}{ Preferred Level of Aroma } & \multirow{2}{*}{ Test Statistics } \\
\hline & Low (1) & Medium (2) & $\operatorname{High}(3)$ & \\
\hline Chinese Ginger & $88 \%$ & $8 \%$ & $4 \%$ & $\chi^{2}$ value: 38.00 \\
\hline Local Ginger & $8 \%$ & $48 \%$ & $44 \%$ & Cramer's V Coefficient: 0.50 \\
\hline Rangoon Ginger & $24 \%$ & $32 \%$ & $44 \%$ & P value: $<0.0001$ \\
\hline \multicolumn{5}{|c|}{ Preferred Level of Aroma vs. Degree of Pungency } \\
\hline \multirow{2}{*}{ Preferred Level of Aroma } & \multicolumn{3}{|c|}{ Degree of Pungency } & \multirow{2}{*}{ Test Statistics } \\
\hline & Low (1) & Medium (2) & High (3) & \\
\hline Low (1) & $60 \%$ & $20 \%$ & $20 \%$ & $\chi^{2}$ value: 17.44 \\
\hline Medium (2) & $36 \%$ & $23 \%$ & $41 \%$ & Cramer's V Coefficient: 0.34 \\
\hline High (3) & $9 \%$ & $57 \%$ & $34 \%$ & P value: 0.002 \\
\hline \multicolumn{5}{|c|}{ Preferred Level of Colour vs. Degree of Pungency } \\
\hline \multirow{2}{*}{ Preferred Level of Colour } & \multicolumn{3}{|c|}{ Degree of Pungency } & \multirow{2}{*}{ Test Statistics } \\
\hline & Low (1) & Medium (2) & High (3) & \\
\hline Low (1) & $20 \%$ & $60 \%$ & $20 \%$ & $\chi^{2}$ value: 5.69 \\
\hline Medium (2) & $21 \%$ & $43 \%$ & $36 \%$ & Cramer's V Coefficient: 0.34 \\
\hline $\operatorname{High}(3)$ & $67 \%$ & $33 \%$ & $0 \%$ & P value: 0.223 \\
\hline \multicolumn{5}{|c|}{ Preferred Level of Colour vs. Preferred Level of Aroma } \\
\hline \multirow{2}{*}{ Preferred Level of Colour } & \multicolumn{3}{|c|}{ Preferred Level of Aroma } & \multirow{2}{*}{ Test Statistics } \\
\hline & Low (1) & Medium (2) & High (3) & \\
\hline Low (1) & $20 \%$ & $40 \%$ & $40 \%$ & $\chi^{2}$ value: 6.70 \\
\hline Medium (2) & $29 \%$ & $29 \%$ & $42 \%$ & Cramer's V Coefficient: 0.37 \\
\hline $\operatorname{High}(3)$ & $83 \%$ & $0 \%$ & $17 \%$ & P value: 0.152 \\
\hline
\end{tabular}

The percentage values shown in each cell indicate the percentage of respondents of the taste panel. For example, ${ }^{\# a}$ total of $0 \%$ respondents ranked Chinese ginger into least preferred level of colour [Low (1)]. 
The row percentages of the significant associations revealed that the preferred level of colour was least for $L G$, medium for $R G$ and high for CG. There was a perfect linear relationship in the association between ginger cultivar and preferred level of colour at a CVC of 1.00 for the association. The highest degree of pungency was received for LG and RG (44 $\%$ and $36 \%$ respondents respectively) whereas CG received the least degree of pungency (72 $\%)$ by the taste panel. The highest preferred level of aroma was observed for both LG and RG (44\% each) and the least preferred aroma was reported for CG $(88 \%)$. The significant association between preferred level of aroma and degree of pungency revealed that aroma and pungency are related to each other.

\section{Antibacterial activity}

Antibacterial activity of the methanol extracts of ginger rhizomes revealed that each ginger cultivar had a significant inhibitory effect against $E$. coli and $S$. aureus compared to the negative $(0.00 \mathrm{~mm}$ of mean DZBI) and positive controls (antibiotic Gentamicin with mean DZBI of $19.65 \mathrm{~mm}$ and $26.32 \mathrm{~mm}$ against $E$. coli and $S$. aureus respectively) However, the reported antibacterial activity against $E$. coli and S. aureus of CG, LG and RG collected from five Districts did not exhibit any major significant variation $(P<0.05)$. Methanol extracts of all the tested ginger samples demonstrated $30 \%$ and $23 \%$ antibacterial activity against $E$. coli and $S$. aureus respectively compared to that of standard antibiotic Gentamicin which was used as the positive control (Figure 02). All of them showed mean DZBI of more than $6.00 \mathrm{~mm}$ against the two pathogens and all three ginger cultivars exhibited similar inhibitory effects against $S$. aureus $(P<0.05)$ (Table 02). When ginger samples of three cultivars collected from five Districts considered together, CG demonstrated significantly highest activity against $E$. coli compared to LG and RG.

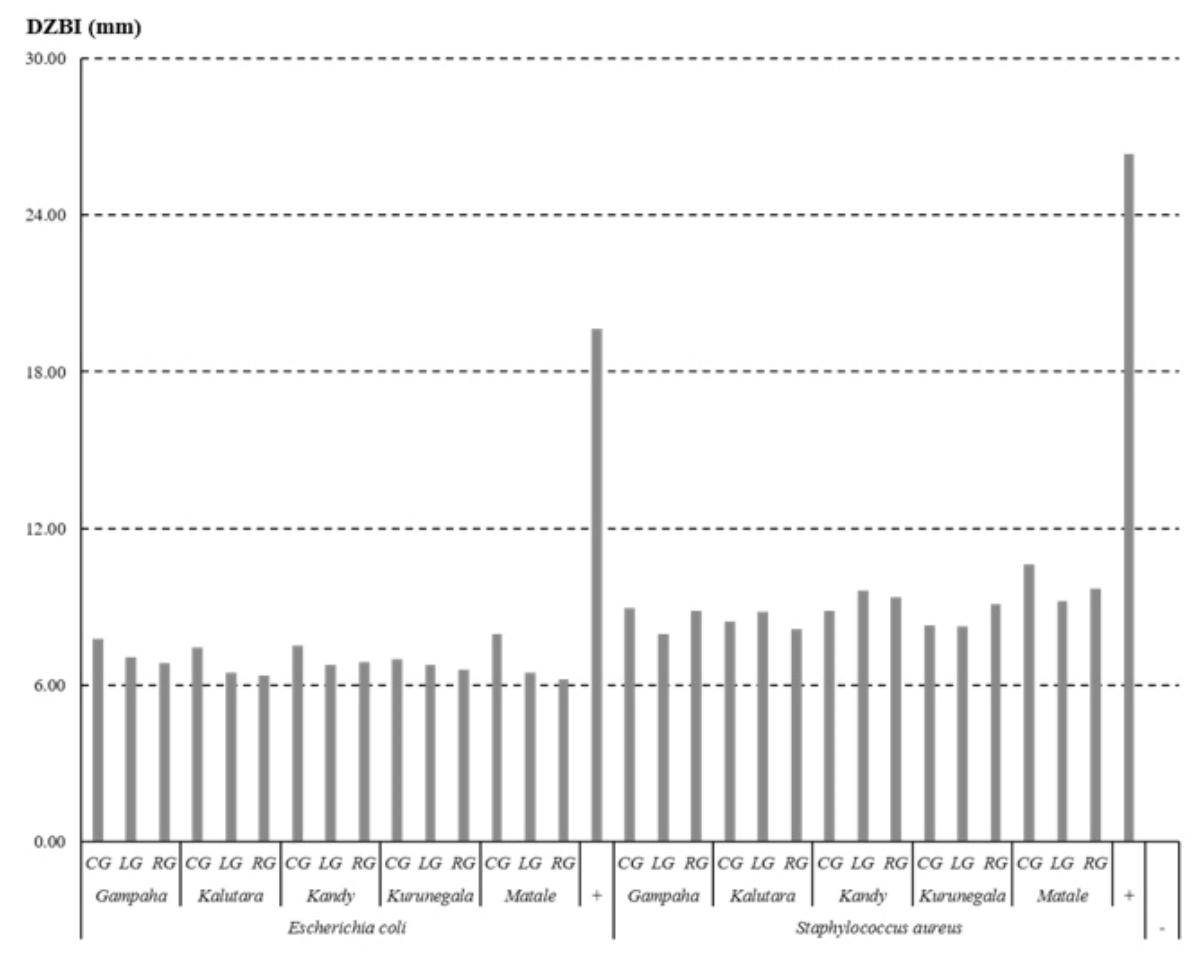

Figure 02: Antibacterial activity shown by methanol extracts of ginger rhizomes. The $\mathrm{Y}$ axis indicates the mean diameter of the zone of inhibition (DZBI) in millimeters (mm). CG: Chinese ginger, LG: Local ginger, RG: Rangoon ginger. Negative (-) and Positive (+) controls are also included. 
Table 02: Antibacterial activity of ginger cultivars

\begin{tabular}{ccc}
\hline Bacterial species & Ginger cultivar & DZBI (mm) \\
\hline \multirow{3}{*}{ E. coli } & CG & $7.54^{\mathrm{b}}$ \\
& LG & $6.72^{\mathrm{c}}$ \\
& RG & $6.59^{\mathrm{c}}$ \\
\hline \multirow{3}{*}{ S. aureus } & CG & $9.03^{\mathrm{a}}$ \\
& LG & $8.76^{\mathrm{a}}$ \\
& $\mathrm{RG}$ & $9.03^{\mathrm{a}}$ \\
\hline
\end{tabular}

Means denoted by the same letters within the column are not significantly different at $P<0.05$.

\section{DNA barcoding}

The genomic DNA extracted from three ginger cultivars yielded a prominent band of approximately 770 bp (Figure 3A). However, another pale band was observed having the size of $500 \mathrm{bp}$ in $\mathrm{CG}$ and RG. The PCR products were subjected to DNA sequencing and a clear sequence chromatogram was obtained only for LG (Figure 3B) but no clear and extended chromatograms were obtained for $\mathrm{CG}$ and $\mathrm{RG}$ even after repeating the DNA sequencing three times (Figures 3C and 3D).

\section{(A)}

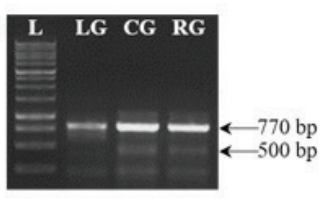

(B)

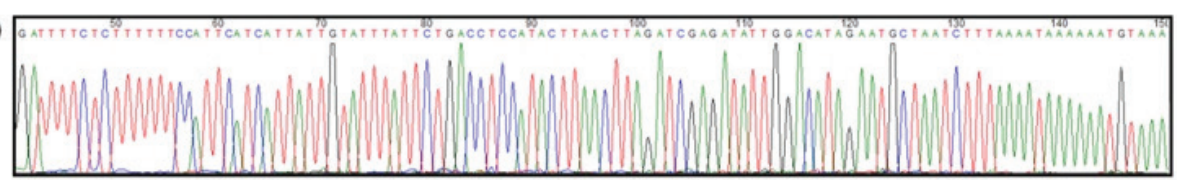

(C)

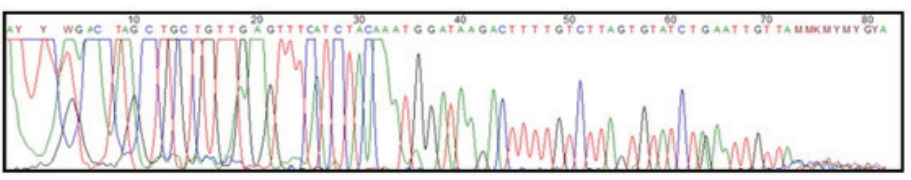

(D)

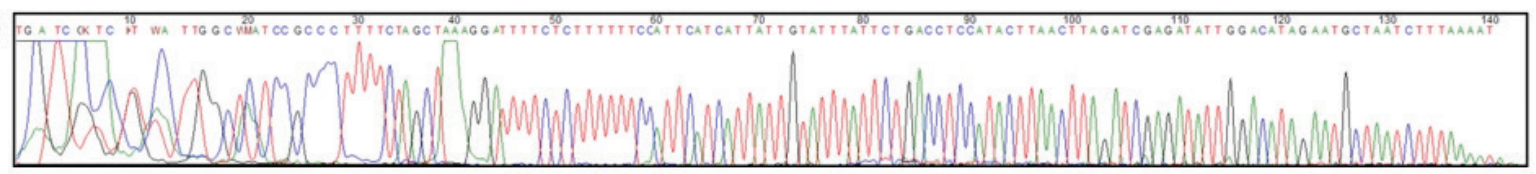

(A): PCR products resolved in 1\% agarose gel L: $1 \mathrm{~kb}$ ladder, LG: Local ginger, CG: Chinese ginger and RG: Rangoon ginger. A band with the size of $770 \mathrm{bp}$ was observed for all three ginger cultivars and a less prominent band of $500 \mathrm{bp}$ was observed for CG and RG.

(B): a part of the chromatogram obtained in sequencing trnH-psbA PCR product of LG (a long readable chromatogram with the DNA sequence).

(C): the complete chromatogram obtained in sequencing trnH-psbA PCR product of CG (chromatogram got prematurely stopped at about 80 bp with no DNA sequence).

(D): the complete chromatogram obtained in sequencing trnH-psbA PCR product of RG (chromatogram got prematurely stopped at about $140 \mathrm{bp}$ with no DNA sequence).

Figure 03: PCR amplification and DNA sequencing of $t r n H-p s b A$ locus for three ginger cultivars. 
The sequence generated for LG was aligned with two other $Z$. officinale trnH-psbA sequences published in GenBank (GenBank ID's were GQ435045.1 and GQ435044.1) and the sequence of the same locus in $C$. longa (KC441355.1). The end regions showing spurious polymorphisms were trimmed off and a $367 \mathrm{bp}$ long region was taken for the final alignment and diversity analysis (Figure 04). This 367 bp region was accepted by GenBank when submitted (the Accession Number assigned by GenBank is KY020752). A total of seven SNPs/INDELs (three INDELs, three transition and one transversion mutations) were observed among the four sequences. The two sequences obtained from the GenBank showed $100 \%$ similarity among them. The sequence of LG showed only $99.2 \%$ genetic similarity to the published trnH-psbA sequences of $Z$. officinale in GenBank. C. longa, which was used as the out-group showed $98.9 \%$ genetic similarity to the $Z$. officinale sequence (Figure 05).
C. Ionga
z. officinale 1
$z$. officinale 2
KC441355.1 CQ435045.1 GQ435044.1
$z$. officinale Local KY020752

\begin{abstract}
GAAATGAACTTAACGACGAGATTTATTATCGTTTCTTGCATGTCTCGTAAAAGACAGAGT GAAATGAACTTAACGACGAGATTTATTATCGTTTCTTGCGTGTCTCGTAAAAGACAGAGT GAAATGAACTTAACGACGAGATTTATTATCGTTTCTTGCGTGTCTCGTAAAAGACAGAGT GAAATGAACTTAACGACGAGATTTATTATCGTTTCTTGCGTGTCT-GTAAAAGACAGAGT

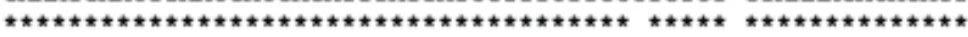

AGGTGCAAATTCTCCCAATTTGTGACCCACCATACGATCCGTTATATAAATAGGTAAATG AGGTGCAAATTCTCCCAATTTGTGACCCACCATACGATCCGTTATATAAATAGGTAAATG AGGTGCAAATTCTCCCAATTTGTGACCCACCATACGATCCGTTATATAAATAGGTAAATG AGGTGCAAATTCTCCCAATTTGTGACCCACCATACGATCCGTTAA-TAAATAGGTAAATG

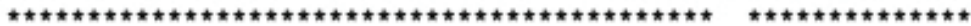

TTCCTTTCCATTATGAATAGCGATTGTATGGCCAATCATTGTGGGTATAATGGTAGATGC TTCCTTTCCATTATGAATAGCGATTGTATGGCCAATCATTGTGGGTATAATAGTAGATGC TTCCTTTCCATTATGAATAGCGATTGTATGGCCAATCATTGTGGGTATAATAGTAGATGC TTCCTTTCCATTATGAATAGCGATTGTATGGCCAATCATTGTGGGTATAATAGTAGATGC

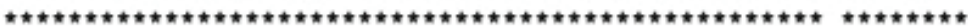

CCGAGACCAAGTTACTATTATTTCTTTCTCTTCCCTCGTGTTGAGTTTTTCAATTTTTTC CCGAGACCAAGTTACTATTATTTCTTTCTCTTCCCTCGTGTTGAGTTTTTCAATTTTTGC CCGAGACCAAGTTACTATTATTTCTTTCTCTTCCCTCGTGTTGAGTTTTTCAATTTTTTC CCGAGACCAAGTTACTATTATTTCTTTCTCTTCCCTCGTGTTGAGTTTTTCAATTTTTGC

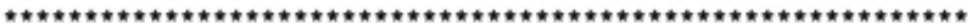

CGATAAATGATTAGCTACAAAAGGGTTTTTTTTTAGTGAACGTGTCATGTCACAGTGTAT CGATAAATGATTAGCTACAAAAGGGTTTTTTTTTAGTGAACGTGTCATGTCACAGTGTAT CGATAAATGATTAGCTACAAAAGGGTTTTTTTTTTAGTGAACGTGTCATGTCACAGTGTAT CGATAAATGATTAGCTACAAAAGGGTTTTTTTTAGTGAACGTGTCATGTCACAGTGTAT ***************************************************************

TACTCCTTTTTTTTTACATTTTTTATTTTAAAGATTGGCATTCTATGTCCAATATCTCGA TACTCCTTTTTTT-TACATTTTTTATTPTAAAGATTAGCATTCTATGTCCAATATCTCGA TACTCCTTTTTTT-TACATTITTTATTTTTAAAGATTAGCATTCTATGTCCAATATCTCGA TACTCCTTTTTTT-TACATTTTTTATTTTAAAGATTAGCATTCTATGTCCAATATCTCGA

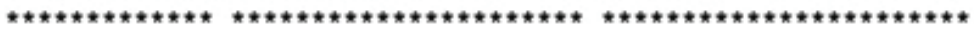

TCTAAGTTAA 370

TCTAAGTTAA

TCTAAGTTAA

TCTAAGTTAA

$\star \star \star \star \star \star \star \star \star \star \star \star *$

C. longa (KC441355.1) (used as the out-group); Z. officinale 1 and 2 (GQ435045.1 and GQ435044.1, respectively) sequences in GenBank; Z. officinale Local (KY020752) (generated in the present study). The numbers in the left shows the cumulative length of the locus in each section of the sequence including the INDELs. The symbol ' $*$ ' indicates the monomorphic bases across the four sequences.

Figure 04: The DNA sequence alignment for the trnH-psbA locus. 


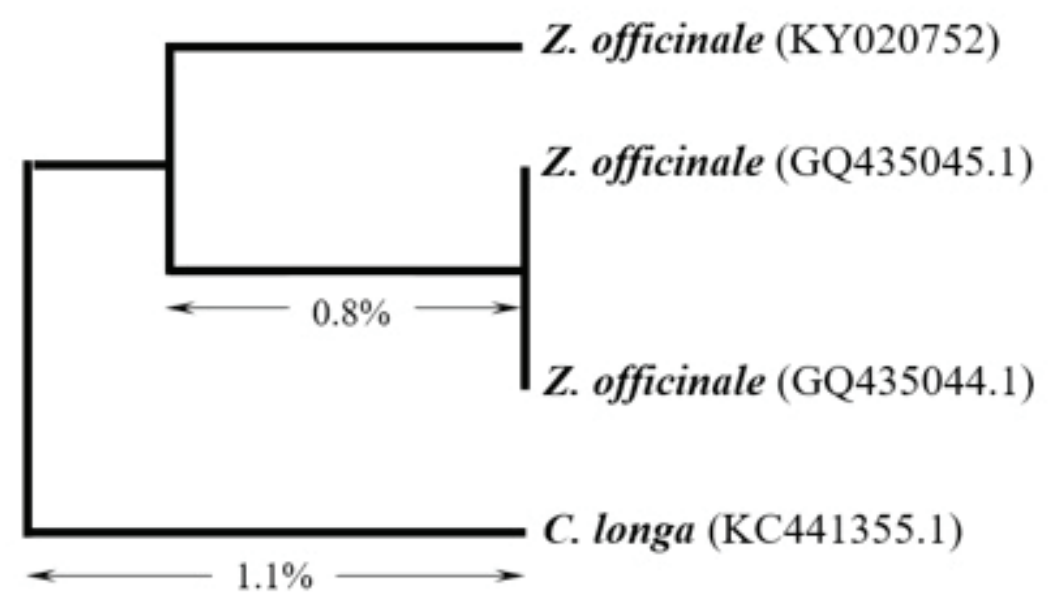

C. longa (KC441355.1) (used as the out-group); Z. officinale 1 and 2 (GQ435045.1 and GQ435044.1, respectively) sequences in GenBank; Z. officinale Local (KY020752) (generated in the present study). The percentage values shown indicate the dissimilarity of trnH-psbA sequences based on the Simple Matching Coefficients (SMC) calculated using SNPs and INDELs observed in Figure 04.

Figure 05: The dendrogram showing genetic distances among the trnH-psbA sequences.

\section{DISCUSSION}

The external and cross sectional appearances of the three ginger cultivars of five Districts were not apparently diverse although the LG rhizomes were slightly smaller in size (Figure 1). The CG and RG were exotic ginger collections introduced to Sri Lanka from China and Myanmar, respectively. Their larger rhizome sizes would be due the breeding and selection done in those countries. The crop improvement attempts to improve ginger germplasm are well reported in China (Wei et al., 2011) and Myanmar (Jatoi et al., 2010).

The association analysis between the preferred level of colour and ginger cultivar revealed significantly higher $(P<0.0005)$ and strongest positive association $(\mathrm{CVC}=1.00)$ among them. The taste panel data indicated that for the preferred level of colour, CG has the highest, LG has the least and RG has the medium preference levels. The association between ginger cultivar and degree of pungency revealed that CG is least pungent and LG and RG are having higher pungency over CG. This association implies that $\mathrm{LG}$ and $\mathrm{RG}$ are more applicable in providing higher pungency (i.e. ginger flavour) for confectionary purposes. Similar to the degree of pungency, CG has the least preferred aroma over LG and RG. In combination, degree of pungency and preferred level of aroma are significantly associated and, LG and RG have higher preferred aroma and degree of pungency over CG. The insignificant associations among the preferred level of colour and degree of pungency and preferred level of aroma indicated that the colour would be regulated by an independent molecular pathway to that of pungency and aroma. The significant association between degree of pungency and preferred level of aroma implies the possibility of having a common molecular basis for pungency and aroma development. The colour development, the aroma and pungency development were found to be independent in species such as chill pepper (Martínez-López et al., 2014). The aroma and pungency in ginger are due to the presence of phytochemicals such as gingerol and shogaol (Elizabeth et al., 2013).

In similar studies, the antibacterial activity of gingerwasevaluated against S. aureus, Klebsiella spp., E. coli, Proteus spp., Enterococcus spp., 
and Pseudomonas spp. using methanol and n-hexane extracts of ginger rhizomes (Hasan et al., 2012; Nikolić et al., 2014; Ahmed et al., 2012; Auta et al., 2011). It was clear from the present study that $S$. aureus was affected more by the methanol extracts of ginger rhizomes than E. coli. The Gram positive $S$. aureus has a single cell membrane compared to Gram negative $E$. coli, which has two membranes in the cell so that antibacterial compounds can penetrate easily into $S$. aureus compared to that of E. coli. Similar results were obtained by Islam et al., (2014) for Gram positive and negative pathogens challenged with ginger extracts. There were no significant differences in antibacterial activity in the rhizome samples collected from the five Districts and three ginger cultivars indicating that there is no significant difference in the concentrations of antibacterial compounds with respect to the ginger cultivar and the Agro-Ecological Zones that they grew. All the ginger cultivars collected from five Districts have at least $6 \mathrm{~mm}$ of DZBI activity against two model pathogens compared to the negative control. This also highlights that antibacterial compounds in ginger rhizomes are synthesized more or less equally regardless of the local soil and climatic conditions. However, the reported antibacterial activity is less compared to a standard antibiotic available in the market (Figure 2). Although, CG is having least pungency and least preferred aroma, it has higher inhibitory activity on E. coli compared to that of $\mathrm{LG}$ and RG. However, all three ginger cultivars are having significantly similar activities over $S$. aureus $(P<0.05)$.

DNA barcoding using trnH-psbA was able to amplify a unique band for LG and the same band and another pale band for $\mathrm{CG}$ and RG (Figure 3A). When these DNA templates were subjected to DNA sequencing, a clear chromatogram was observed only for LG (Figure 3B) but not for CG and RG (Figures 3C and 3D) even after three times of repeated sequencing. These negative results of sequencing could be due to the presence of second band in $\mathrm{CG}$ and $\mathrm{RG}$ for $\mathrm{trnH}$ -
psbA locus. When two templates are available, automated sequencing based on the chain termination method would not be able to produce a clear chromatogram. Although, further studies are needed for confirmation, it can be predicted that $\mathrm{CG}$ and $\mathrm{RG}$ might be having hybrid origin or hetero-plasmic cellular nature that could lead to the presence of double bands. Such heteroplasmic situations or hybrid origins have been reported in wheat (Aksyonova et al., 2005) and Daucus carota (reviewed in McCauley, 2013). Although this kind of chimeric genetic patterns could lead to sterility issues, ginger might have overcome such barriers by genetic fixation through vegetative propagation using rhizomes. The obtained trnH-psbA sequence has shown $0.8 \%$ nucleotide difference to $\mathrm{trnH}$ $p s b A$ sequences of $Z$. officinale deposited in GenBank implying that local ginger has a significant nucleotide divergence from the other Z. officinale types. This could be due to a possible event of speciation or sub-speciation (i.e. divergence) of local ginger from other $Z$. officinale in the world. As reported by Kress and Erickson, (2007) and Pang et al., (2012), either ITS or $r b c L$ barcoding should be done along with $t r n H-p s b A$ to prove this hypothesis of speciation or sub-speciation. The out-group C. longa also has a very high genetic similarity $(98.9 \%)$ indicating that family Zingiberaceae has very low nucleotide diversity in trnH-psbA locus.

\section{CONCLUSION}

The ginger cultivars CG, RG and LG have significantly different levels of preferred colour, aroma and degree of pungency as revealed by the taste panel based association analysis. The CG has the highest, RG has the medium and LG has the least preferred levels of colour. The degree of pungency and preferred level of aroma are higher in LG and RG compared to those of CG. All ginger cultivars have significantly higher antibacterial activity against E. coli 
and $S$. aureus although there is no variation in antibacterial activity in the ginger samples collected from different Districts. The DNA barcoding based on trnH-psbA locus was only able to amplify and generate a sequence for
LG which has $0.8 \%$ nucleotide difference to available trnH-psbA sequences of $Z$. officinale in GenBank implying that LG could be a different species or subspecies of $Z$. officinale.

\section{REFERENCES}

Ahmed, S.A., Jabbar, I.I. and Abdul, H.E. (2012). Study the antibacterial activity of Zingiber officinale roots against some of pathogenic bacteria, Al-Mustansiriya Journal of Science. 3(3): pp. 63-70. DOI: http://dx.doi.org/10.4081/vsd.2015.6080

Ajav, E.A. and Ogunlade, C.A. (2014). Physical properties of ginger (Zingiber officinale), Global Journal of Science Frontier Research. 8(1): pp.1-8 http://journalofscience.org/index.php/ GJSFR/article/view/1401. DOI: http://dx.doi.org/10.3403/30103932

Akintobi, O.A., Onoh, C.C., Ogele, J.O., Idowu, A.A., Ojo, O.V. and Okonko, I.O. (2013). Antimicrobial activity of Zingiber Officinale (Ginger) extract against some selected pathogenic bacteria, Nature and Science. 11(1): pp. 7-15. DOI: http://dx.doi.org/10.2478/ v10136-012-0014-y

Aksyonova, E., Sinyavskaya, M., Danilenko, N., Pershina, L., Nakamura, C. and Davydenko, O. (2005). Heteroplasmy and paternally oriented shift of the organellar DNA composition in barley-wheat hybrids during backcrosses with wheat parents, Genome. 48(5): pp. 761-769. DOI: http://dx.doi.org/10.1139/g05-049

Ali, B.H., Blunden, G., Tanira, M.O. and Nemmar, A. (2008). Some phytochemical, pharmacological and toxicological properties of ginger (Zingiber officinale Roscoe): a review of recent research, Food and Chemical Toxicology. 46(2): pp. 409-420. DOI: http:// dx.doi.org/10.1016/j.fct.2007.09.085

Auta, K.I., Galadima, J.U., Olowoniyi, O.D., Moses, O.O. and Yako, A.B. (2011). Antimicrobial properties of the ethanolic extracts of Zingiber officinale (Ginger) on Escherichia coli and Pseudomonas aeruginosa, Research Journal of Biological Sciences. 6(1): pp. 37-39. DOI: http://dx.doi.org/10.3923/rjbsci.2011.37.39

Aziz, N.A.A., Ahmad, M.I. and Naim, D.M. (2015). Molecular DNA identification of medicinal plants used by traditional healers in Malaysia, Genetics and Molecular Research. 14(4): pp. 15937-15947. DOI: http://dx.doi.org/10.4238/2015.december.7.5

Banerjee, S., Mullick, H.I., Banerjee, J. and Ghosh, A.K. (2011). Zingiber officinale: a natural gold, International Journal of Pharma and Bio Sciences. 2(1): pp. 283-294. DOI: http:// dx.doi.org/10.22376/ijpbs.2017.8.3.bp202-207

Bauer, A.W., Kirby, W.M.M., Sherris, J.C. and Turck, M. (1966). Antibiotic susceptibility testing by a standardized single disk method, American Journal of Clinical Pathology. 45(4): pp. 493-496. DOI: http://dx.doi.org/10.1093/ajcp/57.5.592 
Benson, D.A., Clark, K., Karsch-Mizrachi I., Lipman, D.J., Ostell, J. and Sayers, E.W. (2015). GenBank, Nucleic Acids Research. 43: pp. D30-D35. DOI: http://dx.doi.org/10.1093/nar/ gku1216

Bhargava, S., Dhabhai, K., Batra, A., Sharma, A. and Malhotra, B. (2012). Zingiber officinale: chemical and phytochemical screening and evaluation of its antimicrobial activities, Journal of Chemical and Pharmaceutical Research. 4(1): pp. 360-364. DOI: http://dx.doi. org/10.9734/acsj/2015/16915

Chase, M.W., Salamin, N., Wilkinson, M., Dunwell, J.M., Kesanakurthi, R.P., Haidar, N. and Savolainen, V. (2005). Land plants and DNA barcodes: short-term and long-term goals, Philosophical Transactions of the Royal Society B. 360: pp. 1889-1895. DOI: http://dx.doi. org/10.1098/rstb.2005.1720

Chen, S., Yao, H., Han, J., Liu, C., Song, J., Shi, L., Zhu, Y., Ma, X., Gao, T., Pang, X., Luo, K., Li, Y., Li, X., Jia, X., Lin, Y. and Leon, C. (2010). Validation of the ITS2 region as a novel DNA barcode for identifying medicinal plant species, PLOS ONE. 5(1): e8613. DOI: http://dx.doi. org/10.1371/journal.pone.0008613

Department of Export Agriculture (DEA) (2012). http://www.exportagridept.gov.lk/ 15.08.2016. DOI: http://dx.doi.org/10.18411/d-2016-154

Dorai, T. and Aggarwal, B.B. (2004). Role of chemo-preventive agents in cancer therapy, Cancer Letters. 215(2): pp. 129-140. DOI: http://dx.doi.org/10.1016/j.canlet.2004.07.013

Doyle, J.J. and Doyle, J.L. (1987). A rapid DNA isolation procedure for small quantities of fresh leaf tissue, Phytochemical Bulletin. 19: pp.11-15. DOI: http://dx.doi.org/10.1192/pb.15.11.709

Dunn, G. and Everitt, B.S. (1982). An introduction to mathematical taxonomy, Dover Publications Inc., Mineola, New York, USA. p. 26. DOI: http://dx.doi.org/10.1002/bimj.19650070213

Elizabeth, I., Ifeanyi, G. and Veronica, O. (2013). Production of oleoresin from ginger (Zingiber officinale) peels and evaluation of its antimicrobial and anti-oxidative properties, African Journal of Microbiology Research. 7(42): pp. 4981-4989. DOI: http://dx.doi.org/10.5897/ ajmr2013.6125

Ghasemzadeh, A., Jaafar, H.Z.E. and Rahmat, A. (2010). Antioxidant activities, total phenolics and flavonoids content in two varieties of Malaysia young ginger (Zingiber officinale Roscoe), Molecules. 15: pp. 4324-4333. DOI: http://dx.doi.org/10.3390/molecules15064324

Hasan, H.A., Raauf, A.M.R., Razik, B.M.A. and Hassan, B.A. (2012). Chemical composition and antimicrobial activity of the crude extracts isolated from Zingiber Officinale by different solvents, Pharmaceutica Analytica Acta. 3(9): p. 184. DOI: http://dx.doi.org/10.4172/21532435.1000184 
Hollingsworth, P.M., Forrest, L.L., Spouge, J.L., Hajibabaei, M., Ratnasingham, S., van der Bank, M., Chase, M.W., Cowan, R.S., Erickson, D.L., Fazekas, A.J., Graham, S.W., James, K.E., Kim, K.J., Kress, W,J., Schneider, H., van AlphenStahl, J., Barrett, S.C., van den Berg, C., Bogarin, D., Burgess, K.S., Cameron, K.M., Carine, M., Chacón, J., Clark, A., Clarkson, J.J., Conrad, F., Devey, D.S., Ford, C.S., Hedderson, T.A., Hollingsworth, M.L., Husband, B.C., Kelly, L.J., Kesanakurti, P.R., Kim, J.S., Kim, Y.D., Lahaye, R., Lee, H.L., Long, D.G., Madriñán, S., Maurin, O., Meusnier, I., Newmaster, S.G., Park, C.W., Percy, D.M., Petersen, G., Richardson, J.E., Salazar, G.A., Savolainen, V., Seberg, O., Wilkinson, M.J., Yi, D.K. and Little, D.P. (2009). A DNA barcode for land plants, Proceedings of the National Academy of Sciences. 106(31): pp. 12794-12797. DOI: http://dx.doi.org/10.1073/pnas.0905845106

Islam, K., Rowsni, A.A., Khan, M.M. and Kabir, M.S. (2014). Antimicrobial activity of ginger (Zingiber officinale) extracts against food-borne pathogenic bacteria, International Journal of Environmental Science and Technology. 3: pp. 867-871. DOI: http://dx.doi.org/10.1016/ s2222-1808(14)60758-1

Jatoi, A.S., Kikuchi, A., Ahmad, D. and Watanabe, K.N. (2010). Characterization of the genetic structure of mango ginger (Curcuma amada Roxb.) from Myanmar in farm and genebank collection by the neutral and functional genomic markers, Electronic Journal of Biotechnology. 13(6): http://dx.doi.org/10.2225/vol13-issue6-fulltext-10

Jiang, H., Sólyom, A.M., Timmermann, B.A. and Gang, D.R. (2005). Characterization of gingerolrelated compounds in ginger rhizome (Zingiber officinale Rosc.) by high-performance liquid chromatography/electrospray ionization mass spectrometry, Rapid Communications in Mass Spectrometry. 19: pp. 2957-2964. DOI: http://dx.doi.org/10.1002/rcm.2140

Kambaska, K.B. and Santilata, S. (2009). Effect of plant growth regulator on micropropagation of ginger (Zingiber officinale Rosc.) cv- Suprava and Suruchi, Journal of Agricultural Technology. 5(2): pp. 271-280. DOI: http://dx.doi.org/10.17660/actahortic.2010.853.10

Kress, W.J. and Erickson, D.L. (2007). A two-locus global DNA barcode for land plants: The coding $r b c L$ gene complements the non-coding trnH-psbA spacer region, PLoS ONE. 2(6): e508. DOI: http://dx.doi.org/10.1371/journal.pone.0000508

Kumar, G., Karthik, L. and Rao, B. (2011). A review on pharmacological and phytochemical properties of Zingiber officinale Roscoe (Zingiberaceae), Journal of Pharmacy Research. 4(9): pp. 2963-2966. DOI: http://dx.doi.org/10.11606/d.85.2012.tde-03042012-100652

Martínez-López, L.A., Ochoa-Alejo, N. and Martínez, O. (2014). Dynamics of the chili pepper transcriptome during fruit development, BMC Genomics. 15(1): p.143. DOI: http://dx.doi. org/10.1186/1471-2164-15-143

McCauley, D.E. (2013). Paternal leakage, heteroplasmy, and the evolution of plant mitochondrial genomes, New Phytologist. 200(4): pp. 966-977. DOI: http://dx.doi.org/10.1111/nph.12431

Micklefield, G.H., Redeker, Y., Meister, V., Jung, O., Greving, I. and May, B. (1999). Effects of ginger on gastro-duodenal motility, International Journal of Clinical Pharmacology and Therapeutics. 37(7): pp. 341-346. DOI: http://dx.doi.org/10.1046/j.1365-2982.1998.00124.x 
Nikolić, M., Vasić, S., Đurđević, J., Stefanović, O. and Čomić, L. (2014). Antibacterial and antibiofilm activity of ginger (Zingiber officinale (Roscoe)) ethanolic extract, Kragujevac Journal of Science. 36: pp. 129-136. DOI: http://dx.doi.org/10.5937/kgjsci1436129n

Nmadu, J.N. and Marcus, P.L. (2013). Efficiency of ginger production in selected local government areas of Kaduna State, Nigeria, International Journal of Food and Agricultural Economics. 1(2): pp. 39-52. DOI: http://dx.doi.org/10.9734/ajaees/2017/28949

Pang, X., Liu, C., Shi, L., Liu, R., Liang, D., Li, H., Cherny, S.S. and Chen, S. (2012). Utility of the trnH-psbA intergenic spacer region and its combinations as plant DNA barcodes: a metaanalysis, PLoS ONE. 7(11): e48833. DOI: http://dx.doi.org/10.1371/journal.pone.0048833

Prasad, S. and Tyagi, A.K. (2015). Ginger and its constituents: role in prevention and treatment of gastro-intestinal cancer, Gastroenterology Research and Practice. 2015: http://dx.doi. org/10.1155/2015/142979 DOI: http://dx.doi.org/10.1155/2015/142979

Pruthy, J.S. (1993) Major Spices of India: crop management, post-harvest technology. Indian Council of Agricultural Research, New Delhi. DOI: http://dx.doi.org/10.1002/9781444354652.ch15

Ravindran, P.N. and Babu, K.N. (2005). Ginger the genus Zingiber. CRC Press. USA. DOI: http:// dx.doi.org/10.1017/s0014479705293547

Riaz, H., Begum, A., Raza, S.A., Khan, Z.M.U.D., Yousaf, H. and Tariq, A. (2015). Antimicrobial property and phytochemical study of ginger found in local area of Punjab, Pakistan, International Current Pharmaceutical Journal. 4(7): pp. 405-409. DOI: http://dx.doi. org/10.3329/icpj.v4i7.23591

Saitou, N. and Nei, M. (1987). The neighbor-joining method: a new method for reconstructing phylogenetic trees, Molecular Biology and Evolution. 4(4): pp. 406-425. DOI: http://dx.doi. org/10.1093/oxfordjournals.molbev.a040454

Sang, T., Crawford, D., and Stuessy, T. (1997). Chloroplast DNA phylogeny, reticulate evolution, and biogeography of Paeonia (Paeoniaceae), American Journal of Botany. 84(8): pp. 11201120. DOI: http://dx.doi.org/10.2307/2446155

Sasidharan, I. and Menon, A. (2010). Comparative chemical composition and antimicrobial activity fresh and dry ginger oils (Zingiber officinale Roscoe), International Journal of Current Pharmaceutical Research. 2(4): pp. 40-43. DOI: http://dx.doi.org/10.3403/30103932

Shamsi, S., Tajuddin, and Afaq, S.H. (2010). Spice and medicine: Zingiber officinale, International Journal of Applied Biology and Pharmaceutical Technology. 1(3): pp. 968-973. DOI: http:// dx.doi.org/10.1007/springerreference_69739

Wei, K.H., Miao, J.H., Huang, H.P. and Gao, S.L. (2011). Generation of autotetraploid plant of ginger (Zingiber officinale Rosc.) and its quality evaluation, Pharmacognosy Magazine. 7(27): pp. 200-206. DOI: http://dx.doi.org/10.4103/0973-1296.84230

Yadav, R.K., Yadav, D.S., Rani, N., Sanwal, S.K. and Sarma, P. (2004). Commercial prospects of ginger cultivation in North-Eastern region, ENVIS Bulletin: Himalayan Ecology. 12(2): pp. 1-5. DOI: http://dx.doi.org/10.1163/22941932-90000694 
Zhang, Z.L., Song, M.F., Guan, Y.H., Li, H.T., Niu, Y.F., Zhang, L.X. and Ma, X. (2015). DNA barcoding in medicinal plants: Testing the potential of a proposed barcoding marker for identification of Uncaria species from China, Biochemical Systematics and Ecology. 60: pp. 8-14. DOI: http://dx.doi.org/10.1016/j.bse.2015.02.017 